\title{
Discourse of Faking by Civil Servant Selection Participants on YouTube
}

\section{Diskursus Pengelabuan Peserta Seleksi Pegawai Negeri Sipil di YouTube}

\author{
Yusuf Hadi Yudha ${ }^{1,2}$, Rustono Farady Marta ${ }^{3}$, Hana Panggabean ${ }^{2}$ \\ ${ }^{1}$ Fakultas Psikologi, Universitas Pancasila, Jln. Srengseng Sawah, Jagakarsa, Jakarta Selatan \\ 12640, Jakarta, Indonesia \\ Email: yudha@univpancasila.ac.id \\ ${ }^{1,2}$ Fakultas Psikologi, Universitas Katolik Indonesia Atma Jaya, Jln. Jenderal Sudirman No.51, \\ Jakarta Selatan 12930 Jakarta, Indonesia \\ Email: hanaatmoko@atmajaya.ac.id \\ ${ }^{3}$ Program Studi Magister Ilmu Komunikasi, Program Pascasarjana, Universitas Bunda Mulia, Jln. \\ Lodan Raya No.2, Jakarta Utara 14430, Jakarta, Indonesia* \\ Email: rmarta@bundamulia.ac.id
}

Masuk tanggal : 24-02-2021, revisi tanggal : 05-04-2021, diterima untuk diterbitkan tanggal : 14-04-2021

\begin{abstract}
Technological advances and rapid development of the internet, has pushed YouTube to become one of the new communication media by communicating information through audio and video. This information affects the personality of individuals who have a specific purpose in their efforts to communicate. With YouTube, anyone can freely watch whatever information is presented, and create various content without any permits or censors. This condition made some of content creators leaking a number of psychological tests that should be confidential, by making discussions, as well as tips and tricks on how to get a high score on these tests. This study aims to show how a civil servant candidate openly communicates to the public by creating video content on YouTube about tips and tricks for giving deceptive responses (faking) on the Personal Characteristics Test (TKP) used in civil servant selection test (CPNS) in order to get high score in this test. Analysis of the video using Critical Discourse Analysis from Theo van Leeuwen found that, in order to surpass the predetermined TKP passing grade, test takers were required to play the role of being an ideal figure of a civil servant. As in CPNS selection context, the video also reveals that by faking the test answer, it can increase the chances of participants to get high scores in the test. The self-reporting test format, also helped test takers easily fake the test by selecting answers according to the ideal profile of a civil servant, not answering according to his true state, as is expected in psychological tests in general.
\end{abstract}

Keywords: critical discource analysis, faking, personality characteristic test, Theo Van Leeuwen

\begin{abstract}
Abstrak
Kemajuan teknologi dan berkembang pesatnya penggunaan internet, mendorong YouTube menjadi salah satu bentuk media komunikasi baru untuk menyampaikan informasi melalui tayangan-tayangan berupa audio dan video. Informasi tersebut mempengaruhi kepribadian individu yang memiliki tujuan tertentu dalam upayanya
\end{abstract}


berkomunikasi. Pada kanal YouTube, siapapun dapat dengan bebas menonton dan mengakses informasi apa saja yang disajikan, serta berkreasi membuat berbagai konten tanpa ada batasan perizinan ataupun sensor. Hal ini membuat sejumlah pembuat konten yang tidak bertanggung jawab membocorkan sejumlah tes psikologi yang seharusnya rahasia, dengan membuat pembahasan, serta tips dan trik bagaimana mendapatkan skor tinggi dalam tes tersebut. Penelitian ini bertujuan untuk mengetahui bagaimana peserta seleksi Calon Pegawai Negeri Sipil (CPNS) dan pemberian respon pengelabuan pada pengerjaan Tes Karakteristik Pribadi (TKP) ditampilkan dalam diskursus, khususnya dalam video YouTube berjudul "TIPS DAN TRIK MENJAWAB SOAL TKP CPNS 2019". Analisis terhadap video menggunakan Analisis Wacana Kritis dari Theo van Leeuwen menemukan bahwa, agar dapat melampaui passing grade yang telah ditetapkan, peserta tes dituntut berperan menjadi sosok ideal seorang PNS. Dalam konteks seleksi CPNS, video tersebut mengungkapkan pula bahwa dengan melakukan pengelabuan, dapat meningkatkan peluang untuk mendapatkan skor tinggi dalam tes tersebut. Desain tes yang berupa pelaporan diri, turut membuat peserta tes dapat dengan mudah melakukan faking dengan memberikan jawaban sesuai profil ideal seorang PNS, dan bukan menjawab sesuai dengan keadaan dirinya yang sebenarnya, sebagaimana layaknya yang diharapkan dalam tes psikologi pada umumnya.

Kata Kunci: analisis wacana kritis, pengelabuan, tes karakteristik pribadi, Theo Van Leeuwen

\section{Pendahuluan}

Media daring memiliki karakteristik yang membuat penggunanya dapat mengakses informasi sepanjang sang pengguna memiliki jaringan internet dimana wahana ini memungkinkan penyebaran informasi tanpa halangan spasial (Marta et al., 2019). YouTube merupakan salah satu bentuk media komunikasi baru ditengah era teknologi yang kian canggih (Sampurna et al., 2020), dimana media ini menyajikan berbagai informasi melalui metode audio-visual. YouTube memiliki berbagai keunggulan dalam memenuhi kebutuhan masyarakat untuk mendapatkan berbagai informasi melalui situs ini. Berbagai genre seperti komedi, film, musik, dll, serta berbagai edukasi seperti tutorial-tutorial, review produk, dan lain sebagainya dapat ditemukan di media ini. Selain itu, YouTube melalui berbagai perangkat elektronik (gadget) yang terkoneksi internet, dapat ditonton dimana saja, oleh siapa saja dan kapan saja karena bersifat fleksibel (Faiqah et al., 2016). YouTube juga menyediakan kolom komentar sehingga bersifat interaktif karena siapapun yang menonton dapat memberikan feedback mengenai konten tersebut.

Melalui YouTube (Ayuningtyas \& Abdullah, 2018), siapapun dapat dengan bebas menonton apa saja yang disajikan, serta berkreasi membuat berbagai konten tanpa ada batasan perizinan ataupun sensor. Hal ini menciptakan sebuah permasalahan baru dimana terdapat pembuat konten yang tidak bertanggung jawab, mulai dari memproduksi konten negatif seperti hoaks, pornografi dan pembajakan, serta beberapa tes yang seharusnya dijaga kerahasiaannya, seperti tes psikologi. Maraknya konten-konten di YouTube tentang pembahasan serta tips dan trik bagaimana cara mendapatkan skor tinggi pada tes-tes psikologi, membuat validitas tes psikologi saat ini menjadi 
dipertanyakan, serta hasil ukurnya pun tidak dapat menggambarkan individu yang mengerjakan tes tersebut (Suwartono, 2017).

Penggunaan tes psikologi pada proses seleksi kerja cukup umum oleh kemudahan penyusunan dan administrasi skala psikologi. Pengukuran ini juga relatif lebih murah dibandingkan wawancara (Grace et al., 2020) maupun observasi, dan juga lebih mudah diterapkan karena tidak membutuhkan banyak waktu dan tenaga, khususnya ketika diterapkan pada jumlah peserta yang banyak seperti pada proses seleksi Calon Pegawai Negeri Sipil (CPNS). Namun penggunaan teknik ini perlu memenuhi sejumlah asumsi ketika akan diberikan kepada peserta. Azwar (2013) menjelaskan, asumsi tersebut antara lain peserta dapat memahami butir pernyataan dan instruksi, peserta juga memberikan reaksi yang jujur dan dapat memahami kondisi dirinya dengan baik. Jika hal sebaliknya yang dilakukan, maka skor yang dihasilkan menjadi rendah validitasnya sehingga terdapat syarat kejujuran responden agar hasil tes psikologi tersebut menjadi valid (Azwar, 2013).

Dalam proses seleksi CPNS, terdapat sejumlah tes psikologi yang digunakan, khususnya dalam tahap Seleksi Kompetensi Dasar/SKD (Peraturan Menteri Pendayagunaan Aparatur Negara dan Reformasi Birokrasi/Permenpan RB Nomor 24 Tahun 2019), yaitu: 1). Tes Karakteristik Pribadi (TKP); 2). Tes Wawasan Kebangsaan (TWK); dan 3). Tes Intelegensia Umum (TIU). TKP mengukur perilaku terkait profesionalisme, TIK, sosial budaya, pelayanan publik, hingga jejaring kerja. TWK mengukur penguasaan pengetahuan dan kemampuan mengimplementasikan Bahasa Indonesia, pilar negara, integritas, bela negara, hingga nasionalisme, dimana TIU mengukur kemampuan figural, kemampuan verbal, serta kemampuan numerik.

Dari sejumlah tes yang diujikan dalam seleksi CPNS tersebut, Tes Karakteristik Pribadi (TKP) merupakan salah satu tes yang dianggap sebagai momok peserta CPNS, lantaran banyaknya peserta yang gagal melampaui ambang batas (passing grade) tes tersebut. Kepala Biro Humas Badan Kepegawaian Negara (BKN) Mohammad Ridwan, dalam artikelnya pada detikFinance menyatakan jika momok pada tes seleksi CPNS adalah Tes Karakter Pribadi, karena rata-rata passing grade yang tidak mencukupi. Sebagaimana diketahui, pada tahun 2018, banyak peserta yang nilainya berada di bawah passing grade sehingga gagal lulus tes CPNS. Permasalahan yang muncul saat itu banyak dari peserta ujian CPNS yang tak lolos Passing Grade tahapan SKD, terbanyak karena tersandung di TKP (Kompas.com, 27/01/2020).

Tes Karakteristik Pribadi (TKP) merupakan sebuah tes baik itu aspek kognitif (Fernando et al., 2020) maupun emosi, yang digunakan untuk mengukur jenis dan karakter kepribadian secara psikologi pada peserta CPNS. Tes ini sangat penting dalam seleksi CPNS karena hasil tes diharapkan dapat mengungkap kelebihan dan kekurangan pada diri peserta. Tes ini merupakan pengembangan dari Tes Skala Kematangan (TSK) yang sebelumnya digunakan (bkn.go.id). Materi soal TKP pada seleksi CPNS 2019 (Permenpan RB Nomor 23 Tahun 2019) meliputi: 1). Pelayanan Publik, dimana bertujuan mampu menampilkan perilaku keramahtamahan dalam bekerja yang efektif sehingga dapat mencapai kepuasan maupun kebutuhan masyarakat sesuai dengan kewenangan dan tugas 
yang dimiliki; 2). Jejaring kerja, dengan tujuan mampu membentuk dan membimbing hubungan, bekerja sama, menyampaikan informasi dan berkolaborasi dengan pihak lain secara efektif; 3). Sosial budaya, dengan tujuan mampu bekerja secara efektif dan dapat beradaptasi dalam masyarakat majemuk (Marta, 2018) baik itu dari aspek budaya, suku, agama sebagainya (Marta, 2017); 4). Teknologi informasi dan komunikasi, agar mampu memanfaatkan teknologi informasi secara efektif dalam memajukan kinerja; 5). Profesionalisme, dengan tujuan mampu menjalankan tugas dan fungsi sesuai dengan tuntutan jabatan.

Seperti tes psikologi yang mengukur kepribadian pada umumnya, TKP berbentuk pelaporan diri (self-report) dan tidak memiliki jawaban benar atau salah. Penilaian untuk materi soal TKP apabila menjawab nilai terendah 1 (satu) dan nilai tertinggi 5 (lima) serta tidak menjawab nilainya 0 (nol) (Permenpan RB Nomor 24 Tahun 2019). Meskipun demikian, dalam rangkaian SKD tes ini memiliki bobot yang paling besar dibandingkan TWK dan TIU. Sebagaimana diatur dalam Permenpan RB Nomor 24 Tahun 2019, jumlah keseluruhan tes dalam SKD sebanyak 100 soal, terdiri dari 35 soal TKP, 30 soal TWK dan 35 soal TIU. Passing grade yang ditetapkan dalam peraturan tersebut untuk TKP sebesar 126, TWK sebesar 65, sedangkan TIU sebesar 80.

Tingginya minat lulusan perguruan tinggi untuk menjadi seorang PNS serta kekhawatiran peserta tidak mampu melampaui passing grade yang ditetapkan untuk lulus seleksi CPNS, membuat sejumlah pihak tidak bertanggungjawab berlomba-lomba membocorkan isi dari tes, membuat pembahasan setiap nomor soal yang diberikan, serta mengembangkan tips dan trik bagaimana cara mendapatkan skor tinggi, bahkan tutorial/les/bimbingan belajar baik secara tatap muka maupun online agar dapat melampaui passing grade yang telah ditetapkan. Akibatnya, sejumlah peserta tes dapat dengan mudah memanipulasi jawaban atau memberikan respon yang pengelabuan (faking) agar mendapatkan skor tinggi pada tes tersebut. Hal ini mempengaruhi komunikasi yang terbentuk antara peserta dan pekerjaan yang akan dilakukan ke depannya. Respon yang pengelabuan dilakukan demi mencapai tujuan tertentu, yaitu diterima menjadi pegawai negeri sipil, walau sebenarnya belum tentu pekerjaan tersebut sesuai dengan karakter para CPNS.

Sejumlah penelitian menunjukkan bahwa memberikan respon yang pengelabuan (faking) ini banyak muncul dalam proses seleksi kerja (McLarnon, Goffin, Schneider, \& Johnston, 2016; Schneider \& Goffin, 2012). Paulhus (2002) membedakan respons yang pengelabuan (faking) menjadi dua jenis, yaitu penipuan diri yang timbul ketika individu melakukan pertahanan diri pada situasi yang dianggap menekan atau berbahaya baginya maupun manajemen impresi dengan tujuan meningkatkan daya tarik orang lain terhadap dirinya seperti yang terjadi pada seleksi CPNS. Para peserta tes berusaha menunjukkan jika dirinya yang terbaik agar bisa lolos dalam seleksi, walaupun dengan melakukan manipulasi jawaban yang diberikan untuk membangun kesan positif (Ventimiglia \& MacDonald, 2012) atau memberikan respons yang kurang akurat karena ketidaksadarannya dan faktor pelamar yang keliru menginterpretasikan soal agar hasilnya sesuai dengan harapan penyusun tes (Barker et al., 2015). Hal ini cukup berkaitan dengan identitas diri seseorang, baik dari dimensi lapisan pribadi, 
pengesahan atau pengetahuan orang lain tentang individu tersebut, dan lapisan relasional (Marta, 2018b).

Pemberian respon yang pengelabuan (faking), dapat muncul ketika pelamar memberikan tanggapan yang berlebihan, diperindah, atau tidak jujur, sehingga mengubah hasil yang seharusnya menggambarkan karakteristik asli pelamar (Christiansen, Goffin, Johnston, \& Rothstein, 1994). Peneliti merasa perlu melakukan pendalaman terhadap fenomena ini karena sebagian besar peneliti terdahulu memfokusan kepada dampak distortif respon terhadap validitas atau tinjauan instrumen properti psikometris yang berkaitan dengan kecendrungan jawaban pada respon penipuan (Widhiarso \& Retnowati, 2011), dimana terdapat juga sebagian peneliti yang mulai mempertimbangkan sisi individu, namun masih terbatas pada estimasi abilitas mereka yang diakibatkan dari respon yang pengelabuan (Bell, 1982), serta estimasi terhadap ketepatan respon personal/person fit (Widhiarso, 2012). Penelitian ini bertujuan untuk menganalisa hubungan tentang cara peserta seleksi CPNS (aktor) dan pemberian respon pengelabuan (faking) pada pengerjaan TKP (tindakan) ditampilkan dalam diskursus, guna mencari tahu makna implisit yang terkandung di dalamnya, serta agenda yang ingin dicapai oleh pembuat kontennya melalui diskursus tersebut.

Pembahasan serta tips dan trik mengerjakan TKP, membuat pemirsa mengetahui gambaran secara umum dari salah satu tes psikologi yang digunakan dalam seleksi CPNS, yakni TKP. Sehingga, ketika individu menghadapi atau mengerjakan tes tersebut, ia telah mengetahui soalnya dan juga bagaimana memanipulasi jawaban atau memberikan respon yang pengelabuan (faking), antara lain agar mendapatkan skor tinggi dan lolos seleksi. Perilaku pengelabuan (faking) selain menurunkan validitas hasil pengukuran psikologi, juga dapat menimbulkan kerugian bagi pihak Kementerian atau Lembaga maupun Pemerintah Daerah (K/LPEMDA) yang menerima CPNS hasil seleksi tersebut. Hasil pengukuran yang tidak akurat (valid) (Buana \& Wirakusuma, 2015), membuat (K/LPEMDA) mendapatkan gambaran yang keliru tentang calon pegawainya, sehingga sangat mungkin untuk tidak mendapatkan pegawai sesuai yang dibutuhkannya. Bagi individu (CPNS), perilaku faking juga dapat merugikan diri sendiri, antara lain tidak ditempatkan pada posisi yang sesuai dengan karakteristik pribadi ataupun potensinya, pada saat diterima nantinya, sehingga kinerjanya menjadi tidak optimal. Oleh karena itu, peneliti merasa perlu untuk melakukan penelitian ini.

\section{Metode Penelitian}

Penelitian ini menggunakan pendekatan kualitatif (Sasongko \& Marta, 2018), melalui penggunaan pendekatan kualitatif (Daniar et al., 2020), peneliti dimungkinkan untuk memahami fenomena yang ada baik itu pernah dihadapi oleh subjek penelitian berupa perilaku, persepsi, motivasi, tindakan lainnya secara holistik melalui mendeskripsikannya pada kalimat maupun bahasa dalam suatu konteks khusus melalui metode yang alamiah (Moleong, 2017). Penelitian ini bertujuan melihat fenomena dari pandangan yang beragam sehingga akan mendapatkan pengetahuan baru pada hasil yang menjadi landasan bahan 
pemaparan dari fenomena yang diteliti, karena penelitian ini bersifat eksploratif. Penelitian ini juga menggunakan paradigma kritis (Haryono et al., 2020), dimana penelitian ini melihat sebuah peristiwa dalam konteks yang luas, tidak hanya pada sebuah level tertentu namun juga memperdalam tingkatan lainnya yang memiliki peran dalam sebuah peristiwa (Denzin \& Lincoln, 2006), seperti: konteks atau suasana sosial, politik, budaya hingga ekonomi saat konten video tersebut itu dibuat.

Penelitian ini juga menggunakan metode dari Theo van Leewen (Leeuwen, 2008) mengenai Analisis Wacana Kritis, dimana dapat mengindikasi cara seorang pelaku sosial (orang, kelompok, organisasi, dsb) dan kegiatan (tindakan, perilaku, dsb) ditampilkan dalam suatu teks (Sari, 2018). Model analisis wacana ini dapat digunakan dalam mengindikasi dan mengamati proses yang dilalui objek penelitian yang dimarginalkan posisinya dalam sebuah pemberitaan atau alur cerita teks bergerak (Marta, 2015). Analisis ini dilakukan dengan melihat proses inklusi dan eksklusi yang terdapat dalam wacana media (Andheska et al., 2015). Eksklusi berkaitan dengan bagaimana aktor sosial ditampilkan, sedangkan Inklusi berkaitan dengan bagaimana masing-masing aktor sosial ditampilkan lewat diskursus. Peneliti akan menganalisis bagaimana strategi diskursus yang digunakan oleh pembuat konten video YouTube dalam memberitakan suatu peristiwa melalui proses ekslusi dan inklusi yang dijabarkan oleh Van Leeuwen, peneliti akan melihat apakah ditemukan aktor yang dikeluarkan dan bagaimana video tersebut menghadirkan aktor/pelaku dalam kegiatan/tindakan.

Sumber data ataupun objek dalam penelitian ini adalah video dari YouTube berjudul "Tips dan Trik Menjawab Soal TKP CPNS 2019" yang diunggah oleh akun Madre project pada tanggal 28 Juni 2019. Video yang diunduh peneliti pada tanggal 28 Mei 2020 ini telah ditonton berbagai kalangan sebanyak 8.351 kali, dengan jumlah like sebanyak 244 dan tidak ada yang dislike.

\section{Hasil Penemuan dan Diskusi}

Proses analisis wacana kritis dari Theo Van Leeuwen ini, dimulai dari melihat proses eksklusi yang terdapat dalam wacana media. Eksklusi berkaitan tentang pengeluaran suatu aktor dari pembicaraan (Andalas, 2017) yang merupakan faktor terpenting dalam menganalisis wacana kritis (Leeuwen, 2008). Seorang aktor, dapat ditampilkan dalam suatu pemberitaan tanpa harus mengubah esensi kejadian yang ada pada dalam suatu pemberitaan. Proses eksklusi dapat dilihat dari adanya pasivasi, nominalisasi, penggantiaan anak kalimat. Cara pengubahan kata aktif menjadi pasif yang meupakan bagian dari pasivasi, dimana hal ini berkaitan dengan pengeluaran suatu aktor sosial dari sebuah pemberitaan. Nominalisasi berkaitan dengan mengubah kata kerja menjadi kata benda. Sedangkan pengganti aktor menggunakan anak kalimat (Leeuwen, 2008).

Selanjutnya, proses analisis wacana ini melihat bagaimana proses inklusi yang terdapat dalam wacana media. Inklusi berkaitan dengan bagaimana aktor dalam suatu pemberitaan ditampilkan oleh media (Andalas, 2017). Van Leeuwen (2008) menyebutkan 7 (tujuh) cara media dalam menampilkan aktor. Pertama, terdapatnya perbandingan tindakan dalam suatu pemberitaan melalui diferensiasi- 
indiferensiasi dengan hadirnya kejadian maupun kelompok lain. Kedua, upaya penggambaran kejadian dalam pemberitaan baik melalui peristiwa konkret maupun abstraksi yang berkaitan dengan objektivikasi-abstraksi. Ketiga, pemilihan pengemukaan identifikasi individu baik itu melalui kategori-kategori (jenis kelamin, tas, agama, fisik, dll) pada kaitan nominasi. Keempat, bentuk penjelasan proposisi pertama oleh nominasi-identifikasi yang berkaitan dengan hadirnya proposi tambahan maupun anak kalimat. Kelima, penyebutan maupun identifikasi aktor yang dikemukakan baik itu melalui rujukan pada penyebutan secara jelas (nama) maupun pemahaman berdasarkan anonimitas pada determinasi-indeterminasi. Keenam, pemaparan mengenai golongan aktor sosial baik secara rinci yang disebut maupun komunitas sosial pada kaitan asimilasi. Ketujuh, pengarahan maupun penghubungan terhadap individu maupun kelompol lain yang lebih besar oleh asosiasi-disosiasi yang berkaitan dengan pemberitaan aktor sosial.

Untuk melihat proses ekslusi dan inklusi yang terdapat dalam diskursus video berjudul "Tips dan Trik Menjawab Soal TKP CPNS 2019" yang dibangun oleh akun Madre project berdasarkan pandangan Theo Van Leeuwen, peneliti akan berfokus pada 5 (lima) segmen pada tayangan yang berdurasi 9 menit 46 detik tersebut. Namun secara utuh, gambaran data yang diperoleh dari video tersebut dijabarkan dalam Tabel 1 berikut:

Tabel 1. Pembagian Segmen Video Tips dan Trik Menjawab Soal TKP CPNS

\begin{tabular}{|c|c|c|}
\hline Durasi & Judul Segmen & Garis Besar Isi \\
\hline $\begin{array}{l}00: 00: 00- \\
00: 00: 30\end{array}$ & Pembukaan & $\begin{array}{l}\text { Madre project menyatakan ingin berbagi } \\
\text { tips atau pengalaman mengikuti SKD pada } \\
\text { CPNS tahun } 2018\end{array}$ \\
\hline $\begin{array}{l}00: 00: 31- \\
00: 01: 22\end{array}$ & Pengantar & $\begin{array}{l}\text { Madre project menyatakan SKD pada tahun } \\
2018 \text { berbeda jauh dengan SKD tahun- } \\
\text { tahun sebelumnya. }\end{array}$ \\
\hline $\begin{array}{l}00: 01: 23- \\
00: 02: 05\end{array}$ & $\begin{array}{l}\text { Penjelasan TKP tahun } \\
2018\end{array}$ & $\begin{array}{l}\text { Madre project menjelaskan bentuk soal } \\
\text { TKP berupa esai-esai panjang dan opsi } \\
\text { jawaban yang juga panjang. }\end{array}$ \\
\hline $\begin{array}{l}00: 02: 06- \\
00: 02: 35\end{array}$ & $\begin{array}{l}\text { Segmen 1. Tips } \\
\text { mengerjakan TKP (1) }\end{array}$ & $\begin{array}{l}\text { Madre project menyarankan agar calon } \\
\text { peserta CPNS "belajar membaca cepat". }\end{array}$ \\
\hline $\begin{array}{l}00: 02: 36- \\
00: 03: 08\end{array}$ & $\begin{array}{l}\text { Segmen 2. Kelulusan } \\
\text { CPNS tahun } 2018\end{array}$ & $\begin{array}{l}\text { Madre project menjelaskan, pada tahun } \\
2018 \text { sangat banyak peserta CPNS yang } \\
\text { tidak lulus SKD. }\end{array}$ \\
\hline $\begin{array}{l}00: 03: 09- \\
00: 04: 20\end{array}$ & $\begin{array}{l}\text { Segmen 3. Tips } \\
\text { mengerjakan TKP (2) }\end{array}$ & $\begin{array}{l}\text { Madre project menyarankan agar calon } \\
\text { peserta CPNS "memperhatikan kata kunci" } \\
\text { (pahami kisi-kisi BKN). }\end{array}$ \\
\hline $\begin{array}{l}00: 04: 21- \\
00: 05: 25\end{array}$ & $\begin{array}{l}\text { Segmen } 4 . \\
\text { Miskonsepsi cara } \\
\text { mengerjakan TKP }\end{array}$ & $\begin{array}{l}\text { Madre project menjelaskan, banyak orang } \\
\text { mengira TKP dapat dikerjakan dengan } \\
\text { memilih jawaban yang menggambarkan } \\
\text { orang yang paling baik, rajin, dsb. }\end{array}$ \\
\hline $\begin{array}{l}00: 05: 26- \\
00: 08: 02\end{array}$ & $\begin{array}{l}\text { Segmen 5. Tips } \\
\text { mengerjakan TKP (3) }\end{array}$ & $\begin{array}{l}\text { Madre project menjelaskan, untuk } \\
\text { mendapatkan skor tertinggi dalam TKP, } \\
\text { jawaban yang diberikan sebisa mungkin }\end{array}$ \\
\hline
\end{tabular}




\begin{tabular}{lll}
\hline Durasi & Judul Segmen & Garis Besar Isi \\
\hline & & memberikan 'win-win solution'. \\
\hline 00:08:02- & Rangkuman tips & Madre project merangkum tips yang dapat \\
00:09:26 & mengerjakan TKP & diaplikasikan dalam mengerjakan TKP \\
\hline 00:09:27- & Penutup & Madre project berharap tips nya bermanfaat \\
00:09:46 & dan mendoakan teman-teman yang akan tes \\
& & CPNS 2019 mendapatkan hasil yang \\
& & diinginkan. \\
\hline
\end{tabular}

Sumber: Olahan peneliti dari Adegan Video Tips dan Trik Menjawab Soal TKP CPNS 2019 (Project, 2019)

Pada proses eksklusi di diskursus video tersebut, dapat diketahui bahwa pembuat konten video cukup sering menggunakan strategi penggantian anak kalimat, dibandingkan strategi passivasi dan nominalisasi. Bertujuan menghilangkan pelaku maupun aktor dengan anak kalimat, dasarnya, pembuat konten video percaya bahwa penonton sudah mengetahui maksud yang ingin disampaikan dan juga sebagai efisiensi kata. Akan tetapi, penggunaan strategi ini membuat pelaku menjadi tersembunyi dalam kalimat. Sebagai contoh dalam kutipan video berikut ini:

"Jadi memang beberapa prediksi itu meleset. Dan yang paling, ee...perbedaan yang paling signifikan itu adalah perbedaan tipe soal di ee....TKP, yang mana justru pada tahun sebelumnya itu bisa mendongkrak nilai, justru di tahun kemaren, 2018 itu menjadi momok yang justru menjatuhkan" (Durasi: 00:00:49 - 00:01:14)

Pada kalimat tersebut dapat dilihat bahwa pembuat konten video percaya dan menganggap bahwa penonton tahu siapa yang membuat "beberapa prediksi", dan "menjadi momok" bagi siapa. Oleh karena dianggap tahu dan untuk keefisien kata, peserta seleksi CPNS tahun 2018 sebagai pelaku dihilangkan.

"So..., tips yang pertama, yang bisa temen-temen persiapkan dari sekarang adalah belajar membaca cepat. Asli, jadi bakal kepake banget ketika menghadapi tes yang durasi waktunya itu super singkat." (Durasi: 00:02:05 - 00:02:19)

Pada kalimat di atas, pelaku yang dihilangkan adalah calon peserta seleksi CPNS yang akan mengikuti tes (TKP) di tahun 2019. Pembuat konten video percaya dan menganggap bahwa penonton tahu siapa yang disarankan untuk "belajar membaca cepat" dan "kepake banget" bagi siapa. Begitu pula pada kutipan video selanjutnya.

"Tips yang kedua untuk mengerjakan SKD adalah dengan memperhatikan kata kunci. Ee..jadi sebenarnya BKN itu udah ngasi kisi-kisi ni temen-temen. Jadi temen-temen acuannya ke situ aja. (Durasi: 00:03:09 - 00:03:25)

Kutipan tersebut menggunakan penggantian anak kalimat pada strategi diskursus eksklusi. Penggantian subjek dilakukan dengan menggunakan anak kalimat yang merangkap fungsi sebagai pelaku. Pernyataan kalimat tersebut mengenai bagaimana agar calon peserta seleksi CPNS yang akan mengikuti tes (TKP) di tahun 2019 "memperhatikan kata kunci" dan "mengacu pada kisi-kisi yang diberikan $B K N$ ". Tidak terdapat perubahan maksud tersembunyi yang ingin 
disampaikan oleh pembuat konten pada kalimat tersebut. Sesungguhnya, tanpa anak kalimat pada data, pembuat konten video sudah mampu menyampaikan maksud informasi yang ada. Akan tetapi, melalui penambahan anak kalimat seperti di atas mengakibatkan pelaku itu menjadi tersembunyi dalam kalimat.

Pembuat konten video juga menggunakan strategi passivasi pada proses eksklusi. Pasivasi adalah sebuah strategi diskursus dengan tujuan memproteksi aktor maupun sebuah kelompok dalam bentuk pasif melalui bagaimana seorang pelaku atau kelompok tertentu yang dikeluarkan atau tidak disebutkan dari perundingan pada sebuah diskursus. Sebagai contoh, hal ini dapat dilihat pada kalimat berikut ini:

"Alhamdulillahnya kemaren banyak yang gak lolos, dan diberi kesempatan lagi kan, jadi P2 per L. Artinya tidak memenuhi passing grade tapi lolos, dan berhak untuk mengikuti ....SKB. Tapi kalo misalnya gak ada kesempatan lagi kan, mau gak mau kita harus tetap melakukan yang terbaik dan menjadi yang terbaik." (Durasi: 00:02:37 00:02:55)

Pada kalimat pertama, kata "diberi kesempatan", menunjukkan terdapat aktor lain dari diskursus ini yang dihilangkan dari konten video, yakni penyelenggara seleksi CPNS (BKN). Sebab yang diutamakan di dalam video adalah aktor utama, yakni peserta seleksi CPNS tahun 2018. Dampaknya adalah, penonton lebih memperhatikan dan tertarik untuk melihat aktor utama dibandingkan aktor lainnya. Padahal, dalam potongan transkrip video tersebut, terdapat aktor lain (BKN) yang sebetulnya juga layak untuk diketahui oleh penonton. Selain itu, pembaca menjadi tidak kritis karena dibuat bentuk kalimat pasif yang menghilangkan aktor lain dalam kalimat. Khalayak cenderung lebih akan terfokus pada aktor utama dibandingkan aktor lain sehingga khalayak pembaca tidak menaruh perhatian secara kritis kepada pelaku yang dapat bersembunyi. Strategi ini dapat lebih banyak berdampak pada diselamatkannya pelaku dalam pemberitaan (Chandradewi et al., 2018).

Jika ditelusuri, kejadian yang diceritakan oleh pembuat konten video tersebut dilatarbelakangi oleh pemberitaan sejumlah media pada saat itu yang dikenal sebagai fenomena 'gugur massal CPNS' (Kompas.com, 04/02/2020; Tribun Kaltim.co, 27/01/2020), sehingga menyebabkan banyak instansi di daerah yang mengalami kesukaran dalam mendapatkan pegawai. Wartakotalive (06/11/2018) juga mengungkapkan jika para pelamar CPNS 2018 mengalami kesulitan menemukan jawaban yang paling tepat di soal TKP.

"Soalnya itu merupakan esai-esai panjang, asli panjang banget ..." (Durasi: 00:01:25 $-00: 01: 30)$

Menurut pengakuan sejumlah peserta, hampir seluruh jawaban yang ada pada soal TKP CPNS 2018 merupakan jawaban yang tepat sehingga sulit menentukan jawaban yang paling tepat. Ditambah lagi dengan rendahnya kemampuan memahami bacaan orang Indonesia, khususnya ketika dihadapkan pada teks-teks panjang seperti pada soal TKP tahun 2018. Hasil survei Programme for the International Assessment of Adult Competencies (PIAAC) yang dilakukan oleh OECD untuk Indonesia menunjukkan, di Jakarta (ibukota), 
hanya sekitar 5,4\% penduduk dewasa yang memiliki kemampuan literasi mencapai level 3 dari maksimum 5 level yang harus dicapai (OECD, 2016).

Selain itu, kebiasaan peserta CPNS yang mengandalkan modul-modul tes CPNS yang banyak beredar di pasaran untuk di jual maupun yang bertebaran di internet dalam bentuk persiapan, membuat sebagian peserta menjadi tidak kritis dan kurang siap dalam menghadapi perubahan. Padahal bobot soal seleksi CPNS selalu dievaluasi secara rutin untuk memperhatikan kualitas, seperti yang Kepala BKN Bima Haria Wibisana nyatakan (Liputan6.com, 27/01/2020). Kutipan video berikut juga menunjukkan hal demikian.

Boleh si, ke soal-soal yang ada di luaran sana, misalnya ada yang berbagi soal-soal CPNS lewat instagram, temen-temen misalnya beli dari situ, atau buku-buku yang ada di toko buku, misalnya temen-temen bisa beli di situ” (Durasi: 00:03:25 - 00:03:35)

Meskipun tes psikologi yang digunakan dalam seleksi CPNS mengalami pertumbuhan secara relevan, namun tetap terdapat pergeseran pandangan mengenai tes psikologi ditengah masyarakat. Hal ini membuat membuat masyarakat belajar menekuni, mempersiapkan, bahkan mengingat jawaban ketika akan menghadapi tes psikologis tersebut. Hal ini dapat terlihat dari banyaknya domain pada internet yang menyediakan informasi seputar soal-soal psikologi dalam bentuk visual, numberik maupun bentuk lainnya hingga penjualan buku panduan tes psikologi yang laris menjelang pemilihan CPNS. Video-video pembahasan, tips dan trik mengatasi tes-tes psikologi punpun semakin menjamur dan tidak pernah sepi akan pengunjung dikarenakan faktor kemudahan, kepraktisan dalam waktu yang lebih efisien hingga tidak membutuhkan biaya tambahan.

Maraknya kebocoran tes-tes psikologi seperti pada tes TKP, membuat hasil ukur dari tes tersebut menjadi tidak valid. Ketika menghadapi tes tersebut, para peserta sudah mengetahui jawaban yang akan dipilih sehingga mereka akan memberikan respon tipuan melalui jawaban yang akan mereka berikan dalam tes. Banyak pula ditemukan jika subjek mampu memberikan profil palsu agar dapat diterima dalam proses seleksi karyawan baru dalam sebuah perusahaan(Furnham, 1990). Konstrak yang berkaitan dengan pekerjaanpun diakui sebagai konstrak yang paling mudah dikelabuhi(Furnham, 1990). Hal ini dikarenakan konstrak tersebut dipakai dalam pennilaian dalam konteks memilih karyawan dalam sebuah perseroan, seperti halnya pada pemilihan CPNS ini.

Kutipan berikut menunjukkan fenomena faking masih kerap terjadi ketika pengerjaan TKP pada seleksi CPNS

Jadi begini temen-temen...., temen-temen pernah denger gak sih, kalau misalkan banyak yang bilang gampang dulu TKD eh TKP itu ngerjainnya. Yang penting kita bisa jadi orang yang munafik gitu kan. Semunafik mungkin jawabannya itu adalah jawaban dengan nilai paling tinggi gitu. Artinya kita dituntut harus jadi paling baik, paling bijaksana, paling rajin, paling disiplin, dan sebagainya. (Durasi: 00:04:29 00:04:54)

Penelitian dalam bidang psikologi sudah cukup lama mengamati permasalahan respon palsu yang diberikan oleh peserta ujian pada aspek psikologi. Rancangan yang dipakai untuk menjabarkan distorsi tanggapan inipun 
beragam, baik itu dari respon terpola (response set), nama tipuan atau pengelabuan nama (faking), maupun penyesuaian respon dengan harapan sosial (social desirability) yang memperlihatkan tendensi penjawab dalam memberikan respon palsu. Sejumlah faktor yang mempengaruhi penjawab untuk memberikan tipuan respon, antara lain kehadiran peneliti dan jenis konstrak psikologis yang diukur (Couper, 2001), motivasi responden (Barrick \& Mount, 1996), kondisi pengukuran (Jackson et al., 2000), serta karakteristik individu (Holden \& Jackson, 1981). Ditinjau dari aspek komunikasi, dapat terlihat indikasi citra diri palsu yang dibentuk oleh pelaku melalui interaksi antar individu atau dalam penelitian ini, interaksi CPNS dengan respon yang mereka berikan pada tes tersebut. Interaksi inilah yang kemudian akan mendorong individu untuk melakukan konstruksi identitas mereka secara palsu demi mencapai tujuan komunikasi tertentu.

Video yang diupload oleh Made Project ini juga sedikit banyak memberikan arahan agar peserta CPNS tidak memilih jawaban sesuai dengan keadaan dirinya yang sebenarnya, tetapi memilih jawaban yang sesuai dengan gambaran ideal seorang PNS. Ia menyatakan:

"Jangan jawab ee... apa namanya soal TKP itu berdasarkan dengan kondisinya kita pada saat itu. Jangan terlalu terbawa emosi atau larut dalam kondisi psikologinya kita saat itu. Tapi, jawablah sesuai dengan tanda kutip teori. Teori seharusnya ketika kita ada di posisi itu terus seperti apa." (Durasi: 00:05:42 - 00:06:15)

Pernyataan tersebut sejalan dengan apa yang dikatakan Plt. Kepala Biro Humas Badan Kepegawaian Negara (BKN) kepada Kompas.com, Senin (27/01/2020), bahwa mengerjakan soal TKP memerlukan trik tersendiri. Ia menyatakan:

"Turunkan ego, sehingga kita bisa tahu mana jawaban yang cocok dengan pertanyaan yang diajukan. Intinya jawaban yang paling ideal," (Kompas.com, 27/01/2020)

Terdapat streotip subjektif mengenai profil karyawan yang ideal sehingga terdapat respons tipuan (Mahar et al., 2006).

Jika banyak peserta CPNS mengerjakan TKP dengan cara memilih jawaban yang ideal, bukan sesuai gambaran dirinya yang sebenarnya dengan sengaja, maka skor-skor yang diperoleh peserta tersebut tidak dapat memberikan gambaran karakteristik pribadi asli dari peserta tersebut. Hal ini tentunya akan merugikan instansi tempat bekerjanya nanti. Ditambah lagi, menurut penelitian Schmitt \& Steyer (1993), memberikan respon pengelabuan agar sesuai dengan kepatutan sosial cenderung dilihat sebagai ciri yang bersifatmenetap dibanding dengan ciri yang bersifat temporer. Dengan kata lain, orientasi individu terhadap kepatutan sosial merupakan sebuah kebiasaan dan merupakan atribut individualyang stabil dan menetap. Jika banyak PNS yang memiliki kebiasaan ini, maka tujuan dari seleksi untuk mendapatkan PNS yang memiliki karakteristik pribadi yang berorientasi pada pelayanan publik, jejaring kerja, sosial budaya, teknologi informasi dan komunikasi, serta profesionalisme berpotensi tidak tercapai, bahkan berpotensi untuk mendapatkan PNS yang suka berbohong, pengelabuan, serta tidak mampu memberikan pelayanan yang optimal kepada masyarakat.

Alat tes psikologi merupakan suatu kumpulan kompleks dari disiplin ilmu psikologi, kode etika, dan dedikasi para psikolog secara mendunia. Pengembangan alat-alat tes psikologi bukanlah sesuatu yang murah dan dapat 
diperoleh dalam waktu singkat. Maraknya kebocoran tes di berbagai media, kecerobohan maupun ketidakbertanggungjawaban beberapa oknum, secara perlahan namun pasti menghilangkan esensi kerahasiaan dalam alat tes psikologi. Jika dibiarkan, maka kepercayaan terhadap alat tes psikologi sebagai alat ukur yang akurat, terdepan, dan tentu saja terpercaya semakun terkikis.

Berdasarkan Analisis Wacana Kritis terhadap video Madre project, dapat diketahui bahwa agar bisa melampaui passing grade TKP yang telah ditetapkan, peserta tes dituntut untuk berperan menjadi sosok yang ideal dari seorang PNS. Diletakkan dalam konteks seleksi CPNS, video tersebut mengungkapkan pula bahwa memberikan respon pengelabuan (faking) dalam pengerjaan TKP dapat memperbesar peluang peserta untuk mendapatkan skor tinggi dalam tes tersebut. Desain tes sedemikian rupa turut membuat peserta tes menjawab sesuai teori/gambaran ideal seorang PNS, bukan menjawab sesuai dengan keadaan dirinya yang sebenarnya, sebagaimana layaknya yang diharapkan dalam tes psikologi pada umumnya. Hal ini jelas membuat perbedaan pada pola komunikasi dan psikologi antara pihak terkait yang menyelenggarakan pemilihan CPNS dengan para calon pegawai negeri sipil, karena respon yang diberikan bukan lagi respon sesungguhnya yang menggambarkan identitas peserta.

\section{Simpulan}

Analisa hubungan tentang cara peserta seleksi CPNS (aktor) dan pemberian respon pengelabuan (faking) pada pengerjaan TKP (tindakan) yang ditampilkan dalam diskursus, dapat terlihat melalui makna implisit yang terkandung di dalamnya, dimana terdapat agenda yang ingin dicapai oleh pembuat kontennya melalui diskursus tersebut. Salah satu keunggulan yang dimiliki YouTube adalah kebebasan. Penonton dapat dengan bebas menonton apa saja yang disajikan. Pembuat konten juga bisa berkreasi bebas tanpa ada batasan seperti perizinan ataupun sensor. Namun terdapat kendala jika penonton dan pembuat konten tidak bertanggung jawab dalam kebebasannya. Penonton harus menyaring kembali informasi-informasi yang ada dan tidak menerimanya dengan mentah. Sebagai pembuat konten, harus menyajikan konten yang bertanggungjawab dan tidak melanggar etika. Membocorkan tes psikologi dalam YouTube merupakan salah satu bentuk pelanggaran etika psikologi. Apabila banyak peserta CPNS mengerjakan TKP dengan cara memilih jawaban yang ideal, bukan sesuai gambaran dirinya yang sebenarnya dengan sengaja, maka hasil yang diperolehpun tidak menggambarkan karakteristik pribadi peserta tersebut yang sebenarnya. Jika demikian, maka proses seleksi CPNS pun menjadi sia-sia dan sekedar menjadi rangkaian administrasi proses semata. Selain itu, meskipun tes psikologi mengalami pertumbuhan yang signifikan, namun dimasa akan datang dengan perubahan persepsi tentang tes psikologi ditengah khalayak masyarakat yang mana membuat khalayak belajar menekuni, mempersiapkan, bahkan mengingat jawaban ketika akan menghadapi ujian psikologis tersebut, sehingga membuat tes-tes tersebut menjadi tidak valid dan tidak dapat dipercaya hasil ukurnya. Oleh karena itu, haruslah sangat terjaga kerahasiaan alat-alat tes psikologi terutama oleh orang-orang yang bergerak dibidang psikologi agar tes-tes 
tersebut tetap memiliki fungsi yang sesuai dengan apa yang ingin diukur. Risetriset mengenai pengembangan alat-alat tes psikologi baru, juga perlu digalakkan, agar ke depan dapat menggantikan sejumlah alat tes psikologi yang telah bocor/beredar di mana-mana, sehingga hasil ukurnya pun menjadi tidak dapat dipercaya.

\section{Daftar Pustaka}

Andalas, E. F. (2017). Wacana Solidaritas Muslim Indonesia dalam Teks Pengungsi Muslim Etnis Rohingya pada Media Daring Viva.co.id. JURNAL SATWIKA, $1(2), \quad 8$. https://doi.org/10.22219/SATWIKA.Vol1.No2.8-19

Andheska, H., Maritim, U., \& Ali, R. (2015). Ekslusi Dan Inklusi pada Rubrik Metropolitan Harian Kompas: Analisis Wacana Kritis Berdasarkan Sudut Pandang Theo Van Leeuwen. Bahastra, 34(1). https://doi.org/10.26555/bahastra.v34i1.3974

Ayuningtyas, F., \& Abdullah, A. Z. (2018). Kognisi Sosial Melalui Situs Jejaring YouTube Pada Komunitas Online (Studi Kasus pada Komunitas Online LinkPictureID). Jurnal Komunikasi, 137. https://doi.org/10.24912/jk.v9i2.1076

Azwar, S. (2013). Sikap Manusia: Teori dan Pengukurannya. In Sikap Manusia: Teori dan Pengukurannya. https://doi.org/10.1038/cddis.2011.1

Barker, C., Pistrang, N., \& Elliott, R. (2015). Research Methods in Clinical Psychology. John Wiley \& Sons, Ltd. https://doi.org/10.1002/9781119154082

Barrick, M. R., \& Mount, M. K. (1996). Effects of Impression Management and Self-deception on the Predictive Validity of Personality Constructs. Journal of Applied Psychology, 81(3), 261-272. https://doi.org/10.1037/0021-9010.81.3.261

Buana, I. K., \& Wirakusuma, M. G. (2015). Efisiensi Biaya dan Akuntabilitas Publikasian Hasil (Studi pada Tes Seleksi Penerimaan CPNS di Kabupaten Jembrana dan Karangasem Tahun 2014). 11, 797-822.

Chandradewi, A. A. S. D., Suandi, I. N., \& Putrayasa, I. B. (2018). Analisis Wacana Kritis Theo Van Leeuwen terhadap Pemberitaan Fahri Hamzah pada Portal Berita Detik.com dan Kompas.com. Jurnal Pendidikan Dan Pembelajaran Bahasa Indonesia Vol, 7 (1).

Daniar, A., Marta, R. F., \& Sampurna, A. (2020). Defining Brand Identity of Noesa Woven Fabric through Total Branding in Online Media. Diakom: Jurnal Media Dan Komunikasi, 3(1), 77-88. https://doi.org/10.17933/diakom.v3i1.105

Denzin, N. K., \& Lincoln, Y. S. (2006). No TitleThe Sage Handbook of Qualitative Research, 2nd ed. In Library \& Information Science Research (Vol. 28, Issue 3). https://doi.org/10.1016/j.lisr.2006.05.004

Faiqah, F., Nadjib, M., \& Amir, A. S. (2016). YouTube sebagai Sarana Komunikasi bagi Komunitas Makassarvidgram. Jurnal Komunikasi KAREBA, 5(2), 259-272. https://doi.org/10.1080/14639947.2015.1006801 
Fernando, J., Sasongko, Y. P. D., \& Marta, R. F. (2020). Aktivasi Psikologi Kognitif Melampaui Kesepian dengan Perspektif Komunikasi dalam Film Joker. MEDIALOG: Jurnal Ilmu Komunikasi, 3(1), 109-119. https://doi.org/10.35326/medialog.v3i1.517

Furnham, A. (1990). The Fakeability of the 16 PF, Myers-Briggs and FIRO-B Personality Measures. Personality and Individual Differences, 11(7), 711716. https://doi.org/10.1016/0191-8869(90)90256-Q

Grace, S. B., Tandra, A. G. K., \& Mary, M. (2020). Komunikasi Efektif dalam Meningkatkan Literasi Kesehatan Mental. Jurnal Komunikasi, 12(2), 191. https://doi.org/10.24912/jk.v12i2.5948

Haryono, C. G., Marta, R. F., \& Chinmi, M. (2020). Discursive Intertextualities of RuangGuru due COVID-19 by the Governor of Central Java. Nyimak: Journal of Communication, 233. https://doi.org/10.31000/nyimak.v4i2.2711

Holden, R. R., \& Jackson, D. N. (1981). Subtlety, Information, and Faking Effects in Personality Assessment. Journal of Clinical Psychology, 37 (2). https://doi.org/10.1002/1097-4679(198104)37:2<379::AIDJCLP2270370227>3.0.CO;2-6

Jackson, D. N., Wroblewski, V. R., \& Ashton, M. C. (2000). The Impact of Faking on Employment Tests: Does Forced Choice Offer a Solution? Human Performance, 13 (4), 371-388. https://doi.org/10.1207/S15327043HUP1304_3

Leeuwen, T. van. (2008). Discourse and Practice: New Tools for Critical Analysis. In Discourse and Practice: New Tools for Critical Analysis. https://doi.org/10.1093/acprof:oso/9780195323306.001.0001

Mahar, D., Coburn, B., Griffin, N., Hemeter, F., Potappel, C., Turton, M., \& Mulgrew, K. (2006). Stereotyping as a Response Strategy when Faking Personality Questionnaires. Personality and Individual Differences, 40(7), 1375-1386. https://doi.org/10.1016/j.paid.2005.11.018

Marta, R. F. (2015). Analisis Wacana Kritis Film "Puteri Giok": Cermin Asimilasi Paksa Era Orde Baru. Masyarakat \& Budaya, 17 (1). https://doi.org/https://doi.org/10.14203/jmb.v17i3.323

Marta, R. F. (2017). Refleksi Hibriditas Budaya dalam Pancasila pada Realitas dan Media sebagai Identitas Bangsa. Bricolage: Jurnal Magister Ilmu Komunikasi, 3(01). https://doi.org/10.30813/bricolage.v3i01.841

Marta, R. F. (2018a). Polemik Kebhinekaan Indonesia pada Informasi Instagram @infia_fact terkait Patung Kwan Sing Tee Koen Tuban. Bricolage: Jurnal Magister Ilmu Komunikasi, 3(02). https://doi.org/10.30813/bricolage.v3i02.922

Marta, R. F. (2018b). Integrity Identification in Ethnographicby Biopic of Kwee Tjie Hoei. Jurnal Komunikasi Ikatan Sarjana Komunikasi Indonesia, 3(2). https://doi.org/10.25008/jkiski.v3i2.229

Marta, R. F., Fernando, J., \& Simanjuntak, R. F. (2019). Eksplikasi Kualitas Konten Peran Keluarga Pada Instagram @ Kemenpppa. ETTISAL : Journal of Communication, 4(2), 137. https://doi.org/10.21111/ejoc.v4i2.3702 
McLarnon, M. J. W., Goffin, R. D., Schneider, T. J., \& Johnston, N. G. (2016). To Be or Not to Be: Exploring the Nature of Positively and Negatively Keyed Personality Items in High-Stakes Testing. Journal of Personality Assessment, 98 (5), 480-490. https://doi.org/10.1080/00223891.2016.1170691

Moleong, L. J. (2017). Metodologi Penelitian Kualitatif (Edisi Revisi). In PT. Remaja Rosda Karya.

Paulhus, D. L. (2002). Socially Desirable Responding: The Evolution of a Construct. The Role of Constructs in Psychological and Educational Measurement, 49-69. https://doi.org/10.1097/00005053-195311720-00010

Project, M. (2019). Tips dan Trik Menjawab Soal TKP CPNS 2019.

Sampurna, A., Putri, A. F., Perkasa, M. I. A., MaichelChinmi, \& Marta, R. F. (2020). Peirce' Semiotics of Rinso Advertising's through Total Branding of Integrated Marketing Communication. 1(2), 126-136.

Sari, W. P. (2018). Analisis Wacana Kritis Kasus Penyerangan terhadap Jemaah Ahmadiyah di Cikeusik. Jurnal Komunikasi, 10 (1), 87-94. https://doi.org/10.24912/jk.v10i1.1507

Sasongko, Y. P. D., \& Marta, R. F. (2018). Ekspresi Identitas melalui Relasi Ayah dan Anak pada Iklan YouTube Grab Official. Bricolage: Jurnal Magister $\begin{array}{lll}\text { Ilmu Komunikasi, } & \text { 4(02), }\end{array}$ https://doi.org/10.30813/bricolage.v4i02.1656

Schmitt, M. J., \& Steyer, R. (1993). A Latent State-trait Model (not only) for Social Desirability. Personality and Individual Differences, 14 (4), 519529. https://doi.org/10.1016/0191-8869(93)90144-R

Schneider, T. J., \& Goffin, R. D. (2012). Perceived Ability to Deceive and Incremental Prediction in Pre-employment Personality Testing. Personality and Individual Differences, 52, 806-811. https://doi.org/10.1016/j.paid.2012.01.015

Suwartono, C. (2017). Alat Tes Psikologi Konteks Indonesia: Tantangan Psikologi di Era MEA. Jurnal Psikologi Ulayat, 3 (1), 1-6. https://doi.org/10.24854/jpu12016-51

Ventimiglia, M., \& MacDonald, D. A. (2012). An Examination of the Factorial Dimensionality of the Marlowe Crowne Social Desirability Scale. Personality and Individual Differences, 52, 487-491. https://doi.org/10.1016/j.paid.2011.11.016 